\title{
Fundamentos de lenguaje de los mass-medio
}

\author{
Dra. Pastora Moreno Espinosa \\ Profesora Titular de Redacción Periodística. Universidad de Sevilla
}

La comunicación es un factor esencial en la existencia social del hombre. La información sirve, entre otras cosas, para orientar las conductas de las personas y para mejorar su calidad de vida, es decir, para proporcionar los conocimientos necesarios, de tal manera que el ciudadano medio pueda formarse un juicio propio de los acontecimientos. Además de esto, los medios de comunicación son el instrumento principal de cambio social, desde el momento en que suscitan nuevas ideas, despiertan aspiraciones y promueven tanto el desarrollo político como el económico.

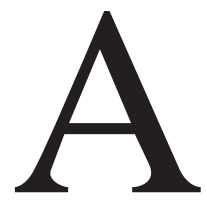

lo largo de la historia, los mass-media han desempeñado siem pre una función social y un servicio público importante. De ahí que sea imprescindible que el periodista sea consciente del rol que cumple en la sociedad, rol que está presidido por la veracidad de las informaciones que transmita.

El lenguaje periodístico es un fenómeno social que repercute en casi todas las esferas de la sociedad. Los mensajes de los vehículos electrónicos son diferentes de los mensajes del periodismo impreso a causa de determinados factores ajenos a los propios medios que les influyen. Como resultado de un conjunto de datos técnicos, políticos, culturales, etc., el mensaje periodístico ofrece características diferenciales suficientemente acusadas según utilice como canal la Prensa escrita o bien la radio o la televisión.

La aparición de la radio en su momento suscitó numerosas controversias, sobre todo, respecto al papel que a partir de ese momento jugaría la prensa escrita.

Pero la crisis inicial que experimentó el periodismo escrito no tardó demasiado en desaparecer. Los dos medios comenzaron a delimitar su terreno y la prensa, tras una redefinición obligada de su función y de sus obje- 
tivos, consiguió un espacio, al igual que la radio, en el complejo mundo receptual de la sociedad contemporánea.

Los adelantos tecnológicos no iban a esperar y poco a poco la inmediatez y la rapidez de las noticias que se producían en todo el globo terráqueo eran asumidas y parcialmente controladas. Los periódicos con sus corresponsales in situ y también la radio.

La televisión surgía años más tarde. Tenía algo que los demás no podían ofrecer: la imagen en movimiento. Este nuevo elemento comunicativo iba a arrasar poco a poco a las audiencias. No había que leer ni prestar atención al amplificador de radio, sólo había que sentarse delante de una pantalla y mirar.

Los demás medios de comunicación supieron adaptarse a la nueva situación del panorama informativo. La radio pensó al principio que su fin estaba cercano, pero se comprobó que el delicado tratamiento de las noticias en televisión, a causa del factor visual de las informaciones, dejaba libre a la radio en su carrera hacia la capacidad de informar con la máxima rapidez e inmediatez de la actualidad acontecida en cada momento.

De la misma forma, cada uno de estos canales de comunicación ha ido conformando su propio código de expresión, tanto lingüístico como paralingüístico, cada cual con sus propios medios y sus propias características inherentes a su misma génesis y desarrollo. Por tanto, es necesario partir de las premisas de una diferente tratamiento y valoración de las informaciones dependiendo del medio, por las limitaciones lógicas.

El mundo que ahora estamos construyendo se va aproximando a esa aldea global, donde la información y la comunicación se adivinan como principales factores de la interacción humana. Las nuevas tecnologías y las nuevas líneas de desarrollo suponen un paso hacia adelante en el que la figura del intermediario informativo, del periodista profesional, se hace imprescindible.

Partiendo de todo lo anterior, consideramos la existencia de tres universos conceptuales y metodológicos en los mass-media como la prensa escrita, la radio y la televisión, con el consiguiente tratamiento diferente de los temas, la ordenación dentro del tiempo, y del espacio, y la particular construcción lingüística del relato, según sus propias condiciones y características en cuanto a la oferta de contenidos informativos y la multiplicidad de mensajes, además de su consiguiente proyección de futuro. Al respecto, Núñez Ladeveze afirma: 
«El medio no sólo es un sistema de distribución de mensajes sino también un sistema de organización de mensajes, y la organización de mensajes preexistentes se convierte, a su vez, en un nuevo mensaje. Al organizar el mensaje el medio lo reelabora... lo reformula, imponiendo de este modo su propia categoría o modo de percibir, de interpretar...

En consecuencia, el medio interesa no como sistema de distribución sino como un sistema organizador de un contenido: los mensajes periodísticos. De acuerdo con este criterio, el medio impone un determinado punto de vista, una forma de percibir los hechos (por tanto) de elaborar mensajes» ${ }^{1}$.

De otro lado, hay que tener en cuenta que las corrientes de especialización periodística se están imponiendo a todos los niveles y sectores de la comunicación. Resulta cada vez más obsoleta la figura del periodista que escribe de todo y vale para todo tipo de información. Frente a esto se esta imponiendo, de forma acelerada, el redactor especializado en áreas concretas que aborda en profundidad la temática que le corresponde. De esta forma, se consigue una mayor exactitud y precisión en el tratamiento del hecho informativo.

Dentro de la propia Prensa escrita «el lenguaje de los periódicos es, en realidad, un conjunto de varios lenguajes especializados» $»^{2}$ Esto se ha dado en llamar, con terminología ya consagrada por el uso, «lenguajes sectoriales» ${ }^{3}$.

Martínez Albertos describe inicialmente el lenguaje periodístico como un lenguaje no literal, próximo a las hablas coloquiales de los sectores cultos de una determinada comunidad de hablantes, que en sus manifestaciones habituales se apoya de modo cuantitativamente importante en oraciones de construcción nominal: «El lenguaje periodístico por antonomasia es el lenguaje periodístico de la prensa escrita, mientras que el «estilo periodístico» sin más matizaciones, responde al estilo informativo, es decir, a los modos expresivos que sirven para la transmisión de datos con cierto ánimo de elaborar un relato objetivo de los acontecimientos» ${ }^{4}$.

NUÑEZ LADEVEZE, L.: El lenguaje de los «media». Pirámide, Madrid, 1991.

CALABRESE, O. Y VIOLI, P.: I giornali. guida alla lettura e all' uso didattico. Edit. L' Espresso, Milano, 1980, p. 106.

3 BECCARIA, G. L.(ED.): I linguaggi settoriali in Italia. Bompiani, Milano, 1973. p.28.

4 MARTINEZ AlBerTOS, J. L.: Curso General ... Op. Cit., p. 204. 
El periódico es, en realidad, un nido de lenguajes, una especie de permanente diccionario de actualidad donde se cobija toda habla por efímera y fugaz que sea. Cada uno de esos lenguajes tiene sus normas y el lenguaje informativo normas muy particulares y trabajosamente elaboradas. Pero todos los textos que aparecen en un periódico, por distintos que sean entre sí, han de tener en común algunas características exclusivas y generales, exclusivas porque son especialmente exigidas por el periódico y generales porque afectan a todos los textos que en él aparezcan.

Hay, pues, una predisposición a la especialización y debe haberla en aquel que se dispone a elaborar un texto para ser publicado.

Por su parte, Mar de Fontcuberta sostiene que «cuando se habla de especialización no hay que referirse al tipo de medio o de audiencia sino a los contenidos. Actualmente se produce una tendencia que resulta revolucionaria en el mundo de los medios de comunicación. La sociedad de masas, nacida en la sociedad industrial, va a dejar paso a una sociedad de colectivos, más propia de la sociedad postindustrial, en la que cada individuo tendrá un peso específico por sí mismo» ${ }^{5}$.

Por tanto, ¿Se podría afirmar que hay como dos fórmulas de lenguaje periodístico: la de todo texto para ser publicado en un periódico (se entiende de información general, no especializada) y la del texto netamente informativo? Creemos que esta distinción ayuda, es clarificadora y responde a una realidad sentida desde la misma fundación del periodismo.

En cualquier caso, nos parece elemental constatar que algo han de tener en común todos los textos que aparecen en un diario por el simple hecho de aparecer en él, en palabras de María Luisa Santamaría: «...Insistir en la existencia de una prensa que promueva la igualación idiomática en un nivel elaborado y culto. Una empresa empeñada en una tarea que informe y contribuya a la justicia, a la verdad, a la convivencia en el seno de una comunidad que, lejos de ser combatiente y épica, intente conducir a los ciudadanos por caminos razonables, aunque estos hayan de promover cambios radicales» ${ }^{6}$.

Y es que la comunicación es un proceso que manifiesta la relación de los hombres entre sí con su contexto social y esta relación se da siempre con intencionalidad: modificar la conducta de los otros y cambiar asimismo el

DE FONTCUBERTA, M.: La noticia. Pistas para percibir el mundo. Barcelona, Paidós, 1993. p. 34.

SANTAMARIA, M. L.: El comentario periodístico. Los géneros persuasivos. Madrid, Paraninfo, 1990. p. 12. 
entorno social. Por consiguiente, la comunicación periodística constituye un proceso de interrelación de individuos y grupos sociales, que se pone de manifiesto con el mensaje. Y la elaboración del mensaje periodístico requiere una estructura formal, una organización lógica de signos con una significación precisa, el ordenamiento de varios signos conforme con un código preestablecido y compartido por un sector social amplio.

Pero, aunque los mensajes se caracterizan por el manejo de técnicas expresivas comunes a todo discurso, no toda la abundante información recibida por los lectores sobre diferentes temas reúne las características necesarias para ser considerada información veraz y completa o más bien desinformación y las circunstancias en las que se ofrecen las noticias.

Para aclarar este concepto, el Diccionario de la Real Academia Española de la Lengua define la palabra «desinformación» como la información intencionadamente manipulada al servicio de ciertos fines ${ }^{7}$.

Este término, que tiene un origen soviético «dezinformatsia», nace al calor de los servicios secretos y se difunde por medio de los franceses.

La Enciclopedia Soviética explica la desinformación como la propagación de informaciones falsas para crear confusión en la opinión pública (1952), o como la difusión en los países burgueses de noticias engañosas o deformadas, utilizadas con profusión como medio de propaganda política a fin de crear confusión en la opinión pública.

Roland Jacquard ubica la «dezinformatsia» al finalizar la I Guerra Mundial. Según él es un concepto introducido en Francia por inmigrantes procedentes de la URSS, que narraron que la policía utilizaba esta palabra para denunciar acciones interiores o exteriores que intentaban obstaculizar la consolidación del nuevo régimen ${ }^{8}$.

En todas estas definiciones que recogemos se manifiesta el vocablo desinformación en engaños conscientes con una intención manipulada.

Teniendo en cuenta estos presupuestos, la desinformación es el hecho informativo que se genera de un incumplimiento de las normas profesionales o linguísticas por parte de un periodista o emisor y que trae como consecuencia un producto informativo incorrecto dirigido a un receptor.

Hemos encontrado el uso de la palabra desinformación con el significado de falta de información en la Conferencia Inaugural de la Facultad de

Diccionario de la Real Academia Española de la Lengua. Espasa-Calpe, Madrid, 1992, p. 507.

JACQUARD, R.: La desinformación: una manipulación del poder. Madrid, Espasa-Calpe, 1988. 
Ciencias de la Información de la Universidad de Sevilla, cuando Amadou Mahtar M'Bow, el ex- director general de la UNESCO, criticó la distancia que separa en el mundo «los 'superinformados' y los desinformados, al tiempo que se acusa de desequilibrio entre emisores y receptores de información. Si el desequilibrio -añade- entre producción y circulación de la información y los programas se encuentra en el interior de cada una de las grandes regiones del mundo e incluso en el interior de cada país, a nivel internacional son las regiones Norte/Sur las más afectadas»?

También M'Bow en dicha conferencia dio como significado al término desinformación que nos ocupa el de información incompleta, ya que aludió a que «la comunicación es un poder que llega a ser un mal compartido tanto en el plano nacional como en el internacional. Cada país tiene sus excluidos o sus desheredados de la comunicación, que no participan más que excepcionalmente.

Por tanto, si desinformación es información incorrecta e incompleta a raíz del incumplimiento de las normas lingüísticas y profesionales, conviene insistir en el buen uso del lenguaje en los medios de comunicación, preocupación que en general es reciente y que los manuales de estilo ${ }^{10}$ o Jornadas monográficas sobre el idioma en los medios han impulsado.

En la misma perspectiva Martínez Albertos subraya: «El escribir bien no es algo que pudiera entenderse como un capricho cultural de corte elitista, sino que una correcta escritura de textos periodísticos es, sobre todo, una garantía de respeto real de los periodistas a uno de los más importantes derechos políticos del ciudadano contemporáneo: el derecho a investigar, recibir y difundir informaciones y opiniones» ${ }^{11}$. Y añade: «Desde el planteamiento de la Escuela Complutense -indica- estamos convencidos de que estos análisis sobre la forma de los mensajes periodísticos tienen una indudable repercusión de carácter político, es decir, desde la perspectiva concreta de cómo es garantizado el derecho de los ciudadanos a recibir libremente una información veraz» ${ }^{12}$.

\footnotetext{
9 MAHTAR M’BOW, A.: Información y comunicación en el mundo contemporáneo. Cuadernos de Comunicación, Facultad de Ciencias de la Información, Universidad de Sevilla, 1989, p. 14.

10 La Agencia Efe fue la pionera en España en la publicación de su Manual de Español Urgente. Madrid, Cátedra, 1990. $7^{a}$ edición. Ha sido analizado por José Fernández Beaumont en El lenguaje del periodismo moderno. Madrid, SGEL, 1987.

11 MARTINEZ ALBERTOS, J. L. , El lenguaje periodístico. Madrid, Paraninfo, 1989. p. 48.

12 Ibid. p. 26.
} 
Subyace en todo ello un debate que mantiene si es posible manipular textos y si la información es tal o merece honestamente ser considerada como tal. Incluso sería interesante recoger esta pregunta en palabras de Luis Núñez Ladeveze: «¿Cuándo una información es sólo información y no propaganda, u opinión, o persuasión, o argucia, o interpretación, o chantaje, o libelo, o etc.?» ${ }^{13}$.

Por su parte, Van Dijk se refiere a la manipulación, es decir, desinformación, como incorrección lingüística: «El hecho de omitir circunstancias que puedan influir negativamente sobre la conclusión final, el no garantizar la validez general de una justificación, o el hecho de ser irrelevante debido a la ausencia de un refuerzo especial puede llevar a una estructura argumentativa incorrecta. Debido a la complejidad de muchos argumentos, en el contexto de la comunicación diaria no siempre resulta posible detectar esa incorrección, de manera que las demostraciones encaminadas a justificar una aseveración y que por lo tanto se emplean persuasivamente en un contexto activo, representan un instrumental frecuentemente empleado para la manipulación de conocimientos y opiniones de los hablantes» ${ }^{14}$.

Por tanto, el análisis lingüístico se manifiesta como el medio de detectar las causas que impiden el derecho a ser informado correctamente y que crean desinformación.

Desde el punto de vista lingüístico Lázaro Carreter plantea una solución que él denomina neutralización del idioma: «Parece evidente que una comunicación que aspira a hacerse general, a ser accesible al mayor número posible de personas, debe tender a la neutralización de su idioma, con vistas a que cualquiera pueda recibirlo como propio y sin sombras; sin las sombras que, para el profano, poseen las lenguas especiales» ${ }^{15}$.

Y todo ello se debe a que el lenguaje es objetivo, pero su uso no siempre. Es incuestionable que para que exista noticia es imprescindible cierta interpretación de la realidad. El lenguaje no es neutro, sino que puede ser fácilmente manipulado y aunque esa manipulación debe ser mínima, es inevitable en ocasiones. A este respecto afirma Pinar Agudiez:

13 NUÑEZ LADEVEZE, L.: El lenguaje de los «media». Introducción a una teoría de la activadad periodística. Madrid, Pirámide, 1979. p. 54.

14 VAN DIJK, T. A.: La ciencia del texto. Un enfoque interdisciplinario. Barcelona, Paidós, 1987. p. 163.

15 LAZARO CARRETER, F. : «El idioma del periodismo, ¿Lengua especial?» en Asterisco Cultural, Publicación de la Fundación Germán Sánchez Ruipérez, Madrid, 1990. N.2. p. 4. 
«No vale hablar de discurso objetivo porque no sirve, atrevámonos a señalarlo un discurso cerrado, monosémico como si la verdad fuera una y única su interpretación. Aquí se niega el acto comunicativo. Primero, porque al receptor se le atribuye esa minoría de edad que imposibilita los juicios propios, los razonamientos autónomos y que aboca a dotarle de argumentos que se concluyen desde la visón adulta y experta del informador-emisor- sujeto de la información. Segundo, porque al mensaje informativo se le perfila con los lápices mitológicos de la objetividad. Y una verdad que sea única, en información, insinúa un dogma, y un dogma no hace un decir sino un juzgar. Tercero, porque resuelve la información en un proceso unidireccional: lo que se pone en juego es un mensaje (hecho-que-se-juzga, desde este plano objetivo) o, dicho de otro modo, lo que pone en juego el emisor (sujeto de la información) es un mensaje para un receptor (objeto de la información)» ${ }^{16}$.

Por otro lado, el periodismo es un modo de hacer interpretación de la realidad. Los receptores de los mensajes periodísticos necesitan un intermediario, tarea que ejercen los medios de comunicación de masas.

«El hombre de hoy, pues, necesita sentirse amparado por los medios de comunicación social, influencias indispensables para su desenvolvimiento y su integración en esta sociedad que apunta a una probable agonía. Se precisa esta integración para que contribuya a la gestación de un futuro mejor, un futuro que le permita asumir su plenitud existencial conforme con sus convicciones y su inalienable proyecto vital» ${ }^{17}$.

Los medios de comunicación de masas pueden llegar a cubrir en parte la grave limitación de espacio y tiempo. Nuestros ojos pueden ser la prensa. Nuestros oídos la radio y la televisión. Según MacLuhan, estos medios se convierten en una prolongación de los cinco sentidos. Afirma:

16 AGUDIEZ CLAVO, P.: «Editorialización y frivolización del discurso periodístico» en Comunicación y Pluralismo. Actas del I Congreso Internacional (Salamanca, del 25 al 27 de noviembre de 1993), Universidad Potificia de Salamanca, 1994, p. 332.

17 AGUILERA, O.: Función y disfunción del mensaje periodístico en relación con la libertad de los receptores, tesis doctoral, Universidad Complutense, Madrid, abril de 1985, original mecanografiado, p. 5. 
«La camiseta es una prolongación de la piel; por lo tanto es una prolongación del sentido del tacto. La rueda es una prolongación del pie. La radio es una prolongación -sin límites- del sentido del oído y de la voz. La televisión es una ampliación -sin límites-del sentido de la vista» ${ }^{18}$.

Al llegar al receptor, resulta entonces que todo mensaje periodístico es el resultado de un proceso complejo, que comprende una serie de elecciones sobre lo que ha de publicarse o leerse en la pantalla o en las ondas, el lugar que debe ocupar y la importancia que debe concedérsele. Lorenzo Gomis basa su teoría en varios supuestos, que son:

«1. La realidad puede fragmentarse en períodos. El único período que se trata de interpretar es el más reciente, que no ha sido interpretado todavía.

2. La realidad puede fragmentarse en unidades independientes (hechos) capaces de interpretarse en forma de textos breves y autónomos (noticias).

3. La realidad interpretada debe poder asimilarse de forma satisfactoria en tiempos distintos y variables: aquel de que disponga cada lector. La interpretación debe poder ser asimilada además por un público heterogéneo.

4. La realidad interpretada debe encajar en un espacio dado, que es variable: aquel de que dispone el periódico.

5. La interpretación que ofrece el medio dispone de una gama de filtros y convenciones (géneros periodísticos), cuyas formas fundamentales y extremas son la información (principalmente la noticia) y el comentario (principalmente el editorial). A esa gama corresponde una diversidad de tonos y usos del lenguaje» ${ }^{19}$.

Por tanto, la información tiene un papel muy importante y en lo que atañe al propósito en la difusión de los mensajes, existen sus diferencias entre los medios impresos y audiovisuales.

Los medios audiovisuales han absorbido la función informativa tradicional de la prensa escrita, por cuanto que pueden cumplir mejor con el requisito de la rapidez en la difusión de las noticias. Los medios impresos han reforzado el periodismo de opinión, pero desarrollando un periodismo más reflexivo, que demanda una interpretación más profunda de la realidad y, por consiguiente, más investigación.

\footnotetext{
8 MAC LUHAN, M.: El medio es el mensaje. Paidós, Buenos Aires, 1969.

19 GOMIS, L.: El medio media (La función política de la prensa). Mitre, Barcelona, 1987, pp. 18-19.
} 
El lenguaje de la radio se diferencia de la prensa escrita porque los textos se escriben para el oído y no para la vista. Hay que prestar especial atención a no perder el interés del público, de modo que a las características de claridad, sencillez y exactitud propias del lenguaje periodístico en general debe unirse el cuidado en la pronunciación y entonación del discurso.

En cuanto al medio televisión, el lenguaje tiene tres dimensiones: la palabra, la imagen y los sonidos. El hecho de que dirija el mensaje tanto al oído como a la vista le permite manejar un nivel emotivo más completo que en otros medios. El periodista se encuentra presente transmitiendo al receptor las imágenes que le proporcionan un conocimiento más completo de los acontecimientos.

Por ello, en todos los medios de comunicación la información juega, pues, un papel decisivo, al mismo nivel que la educación, para una sociedad en la que tan necesaria como el profesor es el periodista. A este respecto opina Westley C. Clark que «el problema de ayudar al ciudadano a conocer lo que necesita saber, aparte de lo que pueda conocer de sí mismo, es enorme para los medios de comunicación de masas ${ }^{20}$.

Además de esto, lo que está claro es que el periodismo es una forma de interpretar la realidad y que nadie puede cubrir por sí mismo el área de las cosas que interesa saber. Las opiniones transmitidas a través del mensaje periodístico abarcan también un espacio inevitablemente más vasto, un lapso de tiempo más largo, un número mayor de cosas de las que podemos observar de forma primaria.

Por tanto, será siempre el rigor del periodista en el proceso informativo especialmente a través del contraste de versiones y de no dejarse llevar por ninguna línea ideológica el que debe determinar fórmulas idóneas que eviten la desinformación del lector.

20 CLARK, W.C.: El periodismo futuro en la comunicación de masas. Troquel, Buenos Aires, 1966, p. 26. 